\title{
ASPECTOS LEGAIS NO GERENCIAMENTO DE RESÍDUOS SÓLIDOS DE SERVIÇOS DE SAÚDE
}

\author{
Lauren Oliveira Lima Bohner ${ }^{1}$ \\ Tanny Oliviera Lima Bohner ${ }^{2}$ \\ Marcelo Barcellos da Rosa ${ }^{3}$
}

\begin{abstract}
RESUMO
São considerados resíduos sólidos de saúde todos aqueles resultantes de atividades exercidas por Serviços de saúde, variando sua natureza em descartes químicos, biológicos, pérfuro-cortantes e lixo domiciliar. O objetivo do presente estudo foi avaliar na literatura a legislação referente ao gerenciamento de resíduos sólidos de saúde, assim como a percepção de estudantes universitários sobre a mesma. Diretrizes previstas na RDC ANVISA no 306/04 e CONAMA no 358/05 dispõem sobre o gerenciamento interno e externo de resíduos sólidos de saúde, entretanto, muitos profissionais operam sem obedecer a legislação. Apesar de existir, no país, diretrizes legais sobre o gerenciamento de Resíduos Sólidos de Saúde, ainda é necessário políticas públicas mais eficientes quanto ao sistema de tratamento e disposição final dos resíduos sólidos., ainda é precário o conhecimento dos estudantes universitários de diferentes cursos sobre os aspectos legais e éticos. Sugere-se um enfoque da Educação ambiental a respeito da problematização para enfatizar no aluno o comprometimento com o meio ambiente.
\end{abstract}

PALAVRAS-CHAVE: Resíduos Sólidos; Serviço de Saúde; Políticas Públicas.

\section{INTRODUÇÃO}

Atendimentos na área da saúde geram diversos tipos de resíduos, variando sua natureza em descartes químicos, biológicos, pérfuro-cortantes e lixo domiciliar (FERNANDES, 2009). Estes, quando dispensados incorretamente, geram enfermidades e contaminação do meio ambiente (RAMALHO et al., 2010). Assim, é necessária uma ampla legislação regulamentando aspectos técnicos e gerenciais sobre os produtos gerados (FERNANDES, 2009). O Plano de Gerenciamento de Resíduos de Serviços de Saúde, disposto pela ANVISA, regulamenta o correto gerenciamento dos mesmos, minimizando o prejuízo ao meio ambiente e, consequentemente, à população (RAMALHO et al., 2010).

Punições penais, civis e administrativas são previstas àquele que praticar atividades lesivas ao meio ambiente. Estabelecimentos da saúde tem o dever de cumprir a legislação aplicável, entretanto, muitos ainda operam sem deter as licenças exigíveis. (SERPA, 2008). Além disso, mesmo que o estabelecimento se encontre em

\footnotetext{
${ }^{1}$ Mestranda em Reabilitação Oral na Faculdade Odontologia de ribeirão Preto (FORP-USP). E-mail: laurenamp@hotmail.com

${ }^{2}$ Especialista em Educação Ambiental pela Universidade Federal de Santa Maria (UFSM)

${ }^{3}$ Professor Doutor na Universidade Federal de Santa Maria (UFSM)
} 
III SEMINÁRII ECDLOGIA

conformidade com a legislação ambiental, estudos mostram que a prevenção da poluição ainda não é enfatizada no ensino da Odontologia (RAMALHO et al., 2010).

É importante ressaltar que, para que se desenvolva uma gestão com enfoque ambiental, deve - se conhecer os aspectos e impactos ambientais que as atividades podem provocar no meio ambiente, ou seja, os elementos que podem interagir com o meio ambiente e a modificação ambiental resultante desta interação (RAMALHO et al., 2010). Estudos realizados em estabelecimentos odontológicos mostram que os profissionais possuem uma preocupação insatisfatória com o meio ambiente e fatores ligados à poluição (SALDANO et al., 2010).

Logo, torna-se necessário uma reflexão e análise crítica por parte dos profissionais da saúde (SERPA, 2008). A consciência individual sobre a saúde ambiental fará uma grande diferença na saúde e qualidade de vida da população. Universidades devem ser objeto de busca constante para obter melhores resultados relacionados à saúde ambiental (LENZI et al., 2002), e a educação ambiental é necessária na busca de alternativas para minimizar o impacto ambiental ( SERPA, 2008).

A educação ambiental está inserida em uma política voltada para a minimização de danos ao meio ambiente e à saúde, e busca englobar diversas áreas do ensino, atuando de forma interdisciplinar, através da promoção de programas educacionais e capacitação da comunidade para a defesa do meio ambiente (SERPA, 2008).

Considerando a importância da educação ambiental na criação do pensamento crítico e reflexivo, o presente estudo tem como objetivo avaliar na literatura a legislação referente ao gerenciamento de resíduos sólidos de saúde, assim como a percepção de estudantes universitários sobre a mesma.

\section{METODOLOGIA}

Foi realizado um levantamento bibliográfico a partir da CAPES, Pubmed e Ebscohost, utilizando as seguintes palavras - chaves: resíduos sólidos, gerenciamento, impacto ambiental. 


métodos corretivos para minimizar os danos à saúde pública e ao meio ambiente. Segundo o artigo 4 paragrafo 1 da RDC CONAMA, cabe aos órgãos ambientais competentes dos Estados, do Distrito Federal e dos Municípios, determinar quais serviços serão objetos de licenciamento ambiental, do qual deverá constar o PGRSS (BRASIL, 2005).

A Política Nacional do Meio Ambiente atua sobre a degradação ambiental, resutante de atividades que prejudiquem a saúde pública e afetem desfavoravelmente a biota. Tem como princípios o equilíbrio ecológico e a proteção dos ecossistemas. (PNMA)

Segundo o artigo 15 da Lei 6.938/81 da Política Nacional do Meio Ambiente, cabe ao poluidor que expuser a incolumidade humana, animal ou vegetal, penas previstas na lei, variando desde uma multa simples até a suspensão do serviço.(PNMA)

\section{DISCUSSÃ̃}

Apesar de existir, no país, diretrizes legais sobre o gerenciamento de Resíduos Sólidos de Saúde, ainda é necessário políticas públicas mais eficientes quanto ao sistema de tratamento e disposição final dos resíduos sólidos (CORREA, 2005).

Silva e Hoppe (2005) analisaram os aspectos de gerenciamento dos municípios pertencentes à bacia hidrográfica do rio Vacacaí, analisando o gerenciamento em hospitais, clínicas e laboratórios. Segundo os autores, os resíduos pérfuro-cortantes são os principais resíduos associados a doenças infecciosas. Entretanto, no estudo verificouse que vários estabelecimentos os misturam junto aos demais lixos. Ainda, apenas 57\% dos locais pesquisados segregam os resíduos químicos, pertencentes ao grupo B. Quanto à sua disposição final, essa é realizada por empresas privadas, sendo os resíduos do grupo A são incinerados ou depositados sem tratamento, enquanto os resíduos do grupo B tem como destino o Aterro de Resíduos Perigosos. Os autores que concluíram que bastante atenção tem sido dada aos resíduos do grupo A, enquanto os demais grupos são descartados sem perspectiva de reciclagem .

Segundo uma pesquisa realizada por Saldano et al. (2010), no qual aplicou-se o sistema SICOGEA para avaliar o índice de sustentabilidade ambiental de clínicas odontológicas, há uma preocupação regular por parte das clínicas sobre o impacto 
ambiental causado pelos resíduos sólidos de saúde. $\mathrm{O}$ estudo mostrou que os estabelecimentos avaliados priorizam o respeito à legislação, e não o impacto sobre o meio ambiente. O estudo corrobora com Ramalho et al. (2010), o qual mostrou que $59,6 \%$ das clínicas odontológicas possuem uma sustentabilidade regular por parte dos aspectos e impactos ambientais, priorizando a legisação.

Corrêa et al. (2005) afirmam que deve-se incluir nos processos pedagógicos ações a respeito da problemática dos resíduos sólidos de serviços de saúde, para enfrentar futuros profissionais para a responsabilidade e comprometimento no assunto. Estudo realizado pelo autor mostrou uma carência na compreensão do assunto por alunos de Enfermagem, Medicina, medicina Veterinária e Odontologia. Os resultados corroboram com os achados de Fernandes (2009), que verificou conhecimentos precários sobre os aspectos legais de Gerenciamento de Resíduos entre estudantes de Odontologia.

Entretanto, um estudo realizado por Serpa (2008), a partir da análise da existência de uma política de educação Ambiental nos currículos dos cursos de Farmácia e Odontologia da Universidade Federal do Ceará, demosntrou a precariedade no quesito meio ambiente nos cursos da saúde. Sugere-se uma interdisciplinariedade em educação ambiental e área da saúde para intercambiar os conhecimentos práticos referentes a cada curso.

\section{CONCLUSÃO}

Foi possível concluir que, apesar da existência da Legislação sobre o Gerenciamento dos resíduos sólidos de saúde, ainda é precário o conhecimento dos estudantes universitários de diferentes cursos sobre os aspectos legais e éticos. Sugerese um enfoque da Educação ambiental a respeito da problematização para enfatizar no aluno o comprometimento com o meio ambiente.

\section{REFERÊNCIAS}

BRASIL, Agência Nacional de Vigilância Sanitária. Resolução - ANVISA. RDC n ${ }^{\text {o }}$ 306, de 07 de dezembro de 2004. 



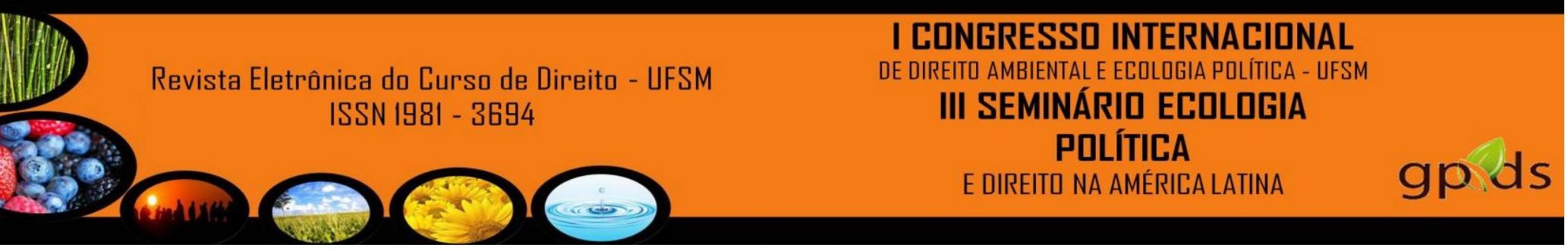

Públicas e Gestão da Educação Superior, Unversidade Federal do Ceará, Fortaleza, 2008.

SILVA, C.E.; HOPPE, A.E. Diagnósticos dos resíduos de serviços de saúde no interior do Rio Grande do Sul. Eng Sanit Ambient, 10 (2 ), 146-151, 2005. 